\title{
Verification of Lightning Protection Measures
}

\author{
Søren Find Madsen \\ Highvoltage.dk and Testinglab Denmark, \\ Denmark
}

\section{Introduction}

During the past decades, the size of wind turbines has increased constantly, which means that a 3MW turbine rising $150 \mathrm{~m}$ above ground level has become today's standard. To optimize the overall efficiency these turbines are often located in clusters in mountainous regions or at off shore locations (wind farms). Such areas are selected as they are often favoured by constant high winds and don't interfere with public interests.

Building very large and heavy constructions in these less accessible areas makes the planning and completion of the project very difficult. The design of the turbine must reflect the situation where spare parts cannot be transported to the site overnight and it might be difficult or impossible to get heavy cranes etc. to the site to replace large components.

To match the output of electrical power, the blades have increased in size as well. In the early 90 's blades had lengths of $15-20 \mathrm{~m}$ and weighed less than a ton. Today blades of very large turbines have passed $60 \mathrm{~m}$ of length and weigh more than 10 tons each. Besides the difficulties in manufacturing and transporting such three blades to the site, they also represent nearly $20 \%$ of the cost of the entire turbine. If one of the blades is damaged for mechanical reasons or due to lightning, the turbine is usually stopped and must be inspected before restart. The outage time of a 2-3MW turbine placed at an optimum location (in terms of wind) can easily cost several thousands of USD a day, adding an important sum to the overall cost of damage.

It is a well-known fact that wind turbines are frequently struck by direct lightning strikes. Especially air terminations must be designed as wearing components with the ability of replacement. The risk of getting struck has also proved to increase with the size of turbines. This fact cannot only be explained by the increase in collection area, but apparently the amount of upward initiated flashes from these relatively high structures has increased drastically as well.

Based on such technical and economic considerations, a serious effort has been made to improve the lightning protection of wind turbines during the past 5-10 years (Holboll et al., 2006; Larsen \& Sorensen, 2003; Madsen, 2006). The contribution has resulted in an improved understanding of the issue of protecting composite blades from lightning discharges, followed by revised manufacturing procedures. Along with implementation of the findings on new blade designs, retrofit solutions for old blades complying with the research are also developed.

After performing extensive research within the area and designing optimum protection measures, the effectiveness of the final solutions must be verified. In June 2010, the revised 
lightning protection standard for wind turbines was published, (IEC 61400-24). Compared to the previous technical report from 2002 (IEC TR 61400-24), this document is stricter and much more demanding. The document includes several requirements for verification of the installed lightning protection systems on sub components. Due to the sizes of modern wind turbines and the difficulties of performing full scale tests, the revised IEC 61400-24 now describes three different methods of verifying the installed lightning protection system:

1. High voltage and high current tests.

2. Demonstration of similarity of the blade type (design) with a previously certified blade type, or a blade type with documented successful lightning protection in service for a long period under lightning strike conditions.

3. Designs that have had successful service experience, by using analysis tools previously verified by comparison with test results or with blade protection.

Bullet No. 2 is the usual choice for industries where the structural design does not change significantly over time, and where a large number of similar objects are in service in different regions of the world. Since the wind turbine industry has grown heavily during the past two decades and new materials and design principles are seen every day, the demonstration of similarity is seldom applicable. This leaves us with the two other methods, testing and modelling. The present chapter describes these two principles of verification, used extensively during the past ten years.

\section{Full scale lightning verification tests}

As seen from the above, verification has become a requirement, and the first proposed action was high voltage and high current testing. Traditionally, high voltage tests have been used to determine the exact location of initial leader attachment points, whereas high current tests are used to foresee the degree of damage once the lightning current appears (Madsen et al., 2006). The lifetime aspect has become an issue of increasing interest, as turbines are often placed in regions of the world that are difficult or expensive to access. At the air termination system (often referred to as receptors on wind turbine blades) the charge associated with the lightning discharge will erode the metal surface and the surrounding laminate. The effect is cumulative, which means that regions in the world where lightning strikes contain a relatively large amount of charge also experience the largest degree of receptor erosion. Consequently, these sites have to be inspected more frequently, or the receptor design must reflect these wearing issues.

The specific energy in the lightning discharge is more related to the mechanical design and the cross sectional areas and fixations of down conductors, but the receptor design and the blade surface in vicinity of the receptor are relevant, too.

When designing full scale tests for verification of the lightning protection effectiveness, the tests should affect the structure (e.g. the blade) with an impact similar to the one experienced during a direct lightning strike to the structure. To get an understanding of the logical steps in developing such a full scale test, the discharge mechanisms on wind turbine blades and the associated verification are described.

\subsection{Lightning discharge to a wind turbine}

The process of lightning attachment and the following lightning current are described various places in literature. In general, a lightning strike to a wind turbine blade begins with a high electric field surrounding the blade tip. This field appears when a lightning leader 
from the cloud approaches the blade (downward initiated lightning strike) or it could be initiated by the field enhancement around sharp and grounded structures when the blade is subjected to the high static field conditions during a thunderstorm (possibly leading to an upward initiated lightning strike if the field is high enough for the inception of leaders).

Following the leader inception from the blade, is the leader interception where the leader from the cloud meets the leader from the blade (at which point it is defined where the lightning will strike), and finally conduction of the lightning current. Initially, the charge present in the leader tip and the leader channel itself will be neutralised by the ground potential from the blade. This charge neutralisation appears at the first return stroke, which is a high amplitude, long duration and highly energetic impulse current. After the first return stroke, additional charges in the thunder cloud have to be neutralized which results in subsequent strokes or continuing currents depending on the charge location in the cloud relative to the leader channel. Subsequent strokes are of short duration with less amplitude and energy content than by the first return stroke. However, due to the high current gradient $(\mathrm{dI} / \mathrm{dt})$, usually the subsequent strokes give high inductive voltage drops and the risk of side flashes within the blade. The continuing or intermediate current is responsible for the main charge transfer. During this sequence several hundreds of coulombs can be transported through the lightning channel to the air termination system, resulting in pitting and erosion on the surface of the air termination system.

\subsection{Initial leader attachment test}

The initial leader attachment test aims at identifying possible lightning attachment points on the turbine construction, typically the blade. The test is performed by elevating the entire blade or the part of the blade in concern (often the blade tip) above a grounded test plane in a high voltage laboratory. The ground plane simulates an equipotential plane of the electric field between an approaching lightning leader and the blade tip (downward initiated flash) or the static background field present prior to an upward initiated flash, Fig. 1.
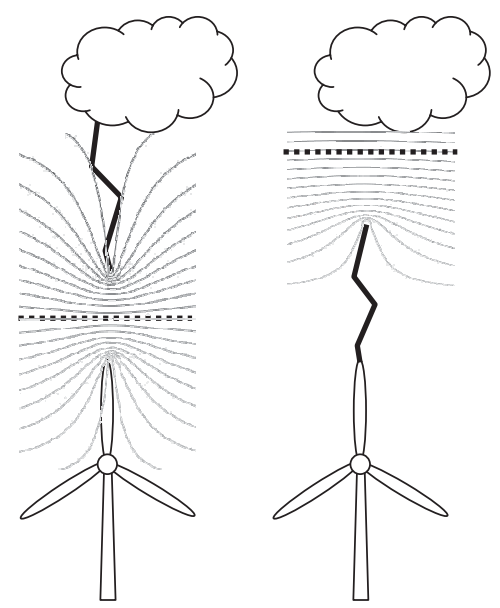

Fig. 1. The ground plane in the test setup simulates the equipotential plane (dotted line) some distance from the blade. Left: A downward initiated strike, Right: An upward initiated strike. 
Subsequently, the elevated blade is connected to the output of a Marx generator injecting high voltage impulses into the lightning protection system of the blade. The voltage waveform is a switching type surge with a rise time of $250 \mu \mathrm{s}+/-20 \%$ and a decay time of $2500 \mu \mathrm{s}+/-60 \%$. The voltage amplitude is selected so that flashover from the blade to the ground plane occurs at the rising flange of the pulse. Such a test simulates the situation in real life where the electric field surrounding the blade suddenly increases to the threshold value for ionization, and thereby initiates the following streamer and leader processes from the blade. The test setup used is shown on Fig. 2, having the blade elevated above a ground plane in the high voltage laboratory.



Fig. 2. Test setup of initial leader attachment test, on a blade tip section, $30^{\circ}$.

On Fig. 3 it is seen how the blade tip is oriented in three different angles to the test plane $\left(90^{\circ}, 60^{\circ}\right.$ and $\left.30^{\circ}\right)$. For each angle, the blade is further more pitched in four different pitch angles to represent all possible orientations, and by injecting three discharges at each position and each polarity, the blade has to experience at least fifty four flashovers during the initial leader attachment test.



Fig. 3. The blade tip is oriented in three different angles to horizontal level and pitched in four different pitch angles for each orientation.

To pass the test, all discharges have to attach to the intended air termination (lightning receptor). If some of the discharges attach elsewhere by puncturing the blade laminate, the design must be reviewed, and the test must be repeated. After the initial leader attachment test is passed, the blade tip can continue the overall test procedure in the high current physical damage test.

\subsection{High current physical damage test}

Once the blade has passed the high voltage initial leader attachment test, it has been verified that lightning discharges most probably will attach to the intended air termination system. 
Then the second task is to determine whether the design can handle the impact from the lightning current.

The following test method is based on an assessment of the annual number of direct lightning strikes to the turbine, the design lifetime and the lightning parameter distribution in IEC 62305.

\subsubsection{Current components in IEC 62305-1}

When a typical blade tip (a passive component with air termination system and down conductor) experiences a direct lightning strike to one of the intended air terminations, the different parameters of the discharge affect the component differently.

\section{Air termination system}

For the air termination system - also called receptors - the charge transfer in the entire flash is important, which means that these components should be tested with 300C of charge transfer in a single long duration stroke (for example $600 \mathrm{~A}$ in $0.5 \mathrm{~s}$ ). For lifetime testing, these values can be adjusted to represent a realistic lifetime. If the receptor cannot withstand the estimated lifetime it must be replaced during maintenance.

\section{Down conductor}

Considering the current path without arcing involved, the resistive heating and magnetic forces are of importance. This is tested by injecting an impulse current representing the first return stroke. The pulse must be of the type $10 / 350 \mu$ s with peak amplitude of $200 \mathrm{kA}$ and a specific energy of $10 \mathrm{MJ} / \Omega$.

\subsubsection{Classes of blade components}

Different parts of the blade bear different risks of getting struck by lightning or conduct parts of the lightning current. Therefore, it is suggested to consider three classes of components which should be tested differently: The current amplitude, charge and specific energy listed in this section refer to the "Single shot test principle" as indicated in the standards, whereas a different approach considering the life time aspect is described in this section.

\section{Class I:}

Class I covers the attachment points on the blade found by the high voltage attachment test. It is believed that this high voltage test method reveals most of the possible locations for direct lightning attachment, meaning that these places are the only ones where current injection simulating a direct lighting attachment should take place. Tests in these areas comprise the following:

1. Injection of a $200 \mathrm{kA} 10 / 350 \mu$ s pulse with a bolted connection to the attachment points (air terminations) considered, aiming at reaching the specific energy of $10 \mathrm{MJ} / \Omega$. This will reveal whether the various down conductor parts are dimensioned properly (thermally speaking), and if fastening of the down conductor can handle the magnetic forces associated with high amplitude currents.

2. Arc attachment of a combined impulse current (30kA or more) and a long duration stroke aiming at transferring the total charge in a flash of 300C. It must be emphasised that the charge only has an impact on the structure if it is injected through an open arc, so that the impulse current ignites the arc. Subsequently, the continuing current should deliver the charge of app. 300C. 


\section{Class II:}

Class II defines the parts of the blade which are not subject to a direct lightning strike. However, by analysis they are seen to carry the entire lightning current. Such parts could be internal joints or connections on the down conductor. The test environment of Class II should contain injection of a $200 \mathrm{kA} 10 / 350 \mu \mathrm{s}$ pulse with a bolted connection to the air terminations considered, aiming at reaching the specific energy of $10 \mathrm{MJ} / \Omega$.

Structures of Class II, which have been tested indirectly during the test of a Class I component (e.g. a connection between the receptor and the down conductor), do not have to be tested again as a Class II component. Such a "receptor - down conductor interface" has achieved the same impact during the Class I test as defined by the Class II test, and therefore it is sufficiently tested by the bolted connection tests of Class I.

\section{Class III:}

Class III defines the parts of the blade which are not subject to a direct lightning strike. By analysis they are seen to carry smaller fractions of the lightning current. If it is possible to identify paths of the down conductor, which in worst case only conducts parts of the lightning currents, it is suggested to test these components with current pulses of less amplitude. If the specific part is believed to carry a fraction $X$ of the entire current, the test conditions for Class III would be Injection of a X-200kA $10 / 350 \mu$ s pulse with a bolted connection to the air terminations considered, aiming at reaching the specific energy of $\mathrm{X}^{2} \cdot 10 \mathrm{MJ} / \Omega$.

Scaling of the current values means, that if a certain parallel part of the down conductor is believed to carry half the current in worst case, the amplitude of the $10 / 350 \mu$ s pulse should be $1 / 2 \cdot 200 \mathrm{kA}=100 \mathrm{kA}$. The specific energy would then be reduced to $(1 / 2)^{2} \cdot 10 \mathrm{MJ} / \Omega=2.5 \mathrm{MJ} / \Omega$.

\subsubsection{Test method}

For impulse current testing, the size and geometry of the test sample often plays a limited role in reaching the desired peak current amplitudes and current gradients. Therefore, it is advised to test as small specimens as possible only containing the relevant parts (receptors, connection components etc.).

The DC current transferring the charge of $300 \mathrm{C}$ is either generated by shorting a large battery bank through the specimen, or by rectifying the output of an AC set and connecting it across the specimen. In either case the charge only applies damage if it is injected through an open arc, hence the voltage of the source must be high enough to maintain the arc for the specified period of time. Ignition of the arc is done by an impulse current from a generator with a higher output voltage.

In principle, an impulse current generator responsible for applying the specific energy consists of a capacitor bank, which have been charged to a certain voltage and afterwards discharged through the test specimen. If the long tale of the $10 / 350 \mu$ s is to be obtained with a minimum of capacitance in the bank, the crowbar principle should be used. This principle couples an inductance in series with the test specimen and shorts out the capacitor bank when the current amplitude is at its maximum. The two types of generators are often combined, which means that a 30-50kA oscillating impulse current can initiate the continuous current resulting in an overall charge transfer of $300 \mathrm{C}$.

\subsubsection{Bolted connection}

By identification of structures, which will experience only the conduction of lightning current and not the impact of a direct strike (Class II), the specific energy of the impulse 
current is of interest. In these cases, terminations from the generator to the test specimen should be bolted connections, aiming at minimizing the overall impedance of the test circuit, and thereby increasing the specific energy of the current pulse, Fig. 4.

\subsubsection{Arc injection}

At lightning attachment points or other places where arcing in connection with the lightning current occurs (Class I), a test using open arcs must be conducted. Open arc attachment represents a relatively high impedance of the test circuit. The specific energy is limited, but the charge transfer will remain unaffected. Since the charging voltage is limited for current generators, the arc must be ignited by a thin ignition wire from the generator electrode to the specimen. Furthermore, the generator electrode must be of a jet diversion type, so that melted metal and plasma from the electrode material is blown away from the test specimen, Fig. 4.

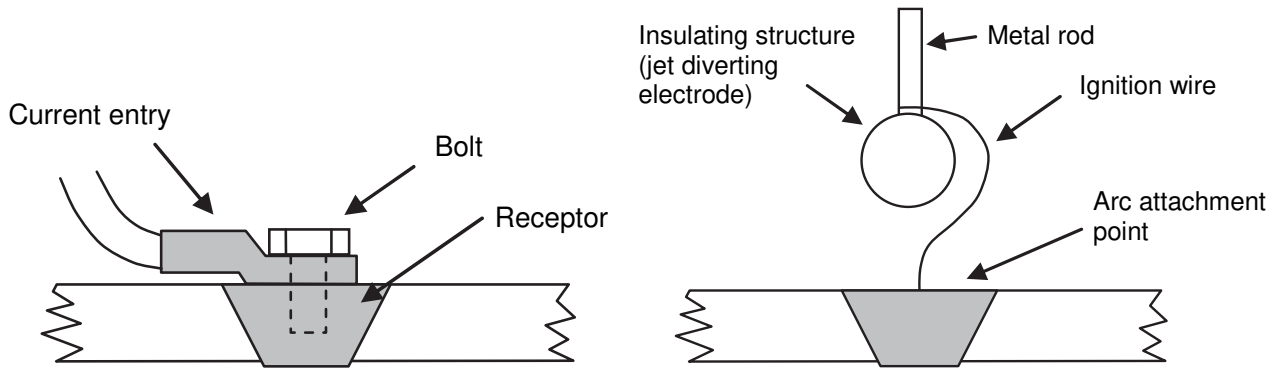

Fig. 4. Left: Bolted connection to an air termination system, Right: A thin ignition wire and a jet diverting electrode are used when arc injection tests are conducted.

\subsubsection{Life time impact}

The frequency of lightning attachments to wind turbines varies considerably from one site to another. In situations where wind turbines are struck several times a year, or even more often, the life time aspect becomes important. The issue is to determine how many strikes the turbine can withstand before it needs service or replacement of wearing components. In the IEC 61400-24, it is even a requirement that the turbine can remain operational between scheduled service/maintenance. This is ensured by verifying that the impact due to lightning is based on the expected amount of strikes and the severity of those strikes. Based on the probability density functions given in the IEC 62305-1, suggestions can be defined on how to simulate 20 years of lifetime for a blade on a typical site (Bertelsen et al. 2007). The methodology used suggests the following number of strikes and amplitudes for the different types of tests, Table 1 .

\begin{tabular}{|l|l|l|l|}
\hline \multicolumn{2}{|c|}{ Bolted connection } & \multicolumn{2}{c|}{ Arc attachment } \\
\hline Number of impacts & Amplitude [kA] & Number of impacts & Charge [C] \\
\hline 2 & 200 & 4 & 300 \\
\hline 3 & 150 & 4 & 200 \\
\hline 8 & 100 & 6 & 150 \\
\hline 7 & 50 & 6 & 100 \\
\hline
\end{tabular}

Table 1. Peak current values for bolted connection with $10 / 350 \mu$ s waveform and charge content in the arc attachment test, simulating 20 years of lifetime (Bertelsen et al. 2007). 
By following these principles, each air termination system is affected with a total of $3500 \mathrm{C}$ in 20 discharges, and each part of the down conductor is exposed to 20 current pulses between $50 \mathrm{kA}$ and $200 \mathrm{kA}$ with specific energies up to $10 \mathrm{MJ} / \Omega$.

\subsection{Test evaluation}

The new standard IEC 61400-24 requires that wind turbine lightning protection systems are verified by either testing or numerical simulation. If simulation is used, the models used in the computation must be validated by testing.

The initial leader attachment test is nearly a pass/fail test, since the finite number of discharges either attaches correctly to air termination system or punctures the blade. Considering the high current test, it is a little more diffuse, since all impulse currents will introduce some degree of damage or wearing on the receptor or other components in the path of the lightning current. The current waveforms, peak amplitude, specific energy, and charge transfer should be recorded for each discharge. Besides this factual information, each discharge should be followed by a subjective analysis of whether the damage is acceptable. Components as lightning receptors might suffer considerably from the charge transfer in an arc attachment test, why the possibility of replacing such components as part of scheduled maintenance should be discussed. In general the results and the evaluation pass/fail depend on the predefined success criteria.

\subsection{Full scale lightning verification tests on other equipment, Nacelle, HUB, etc}

Besides testing blade and blade tip sections which is the most frequently used test, full scale tests of other components are also conducted. When the blade or the nacelle is struck directly, the lightning current will always flow in the nacelle structure or close to the equipment located within or adjacent to the nacelle. For this reason, the immunity of the equipment must be verified, which has traditionally been done using the generic EMC standards, the IEC 61000-4-5 among others. To use these standards, the impact (in terms of current and voltage pulses) of the equipment at its actual position must be defined. To estimate the current level on a shielded cable within a complex nacelle structure is very difficult, and consequently the results of the estimation may be rather unreliable. Then the most straight forward solution is to conduct full scale tests and let the laws of physics decide the impact.

For this purpose, some test facilities offer to costumers full scale tests, in which the entire structure (Nacelle, HUB, etc.) is exposed to the lightning environment, i.e. impulse voltage and impulse currents as the ones used for blade verification. The entire system is operated under normal conditions, meaning that the blade bearings in a HUB is moving, the HUB on a nacelle is rotating, ensuring that all equipment is operational and that all sensors are active. By injecting realistic lightning currents in the range of 50kA to $200 \mathrm{kA}$, and evaluating the output of all sensors and control systems, the immunity of the equipment can be verified.

Since inductive and capacitive couplings are included per default, there is no risk of over testing, and after passing the full scale equipment test, the manufacturer can definitely claim that their products meet the requirements. At the time of publication, this type of testing principle is quite new. For a couple of years, tests on aviation lights, wind sensors, GPS antennas and similar items have been conducted on a regular basis. The equipment is mounted on a mock-up of the actual installation, creating a similar impact in terms of the 
magnetic and electric field. An image of such a test is seen on Fig. 5. Tests on larger structures like wind turbine HUBs and nacelles have only been conducted a couple of times, and the results and images of such tests have not yet been published. However, it is expected that full scale tests on large equipment will be standard of near future, since the complexity of these systems makes it easier and more reliable to test on entire structures including all couplings.
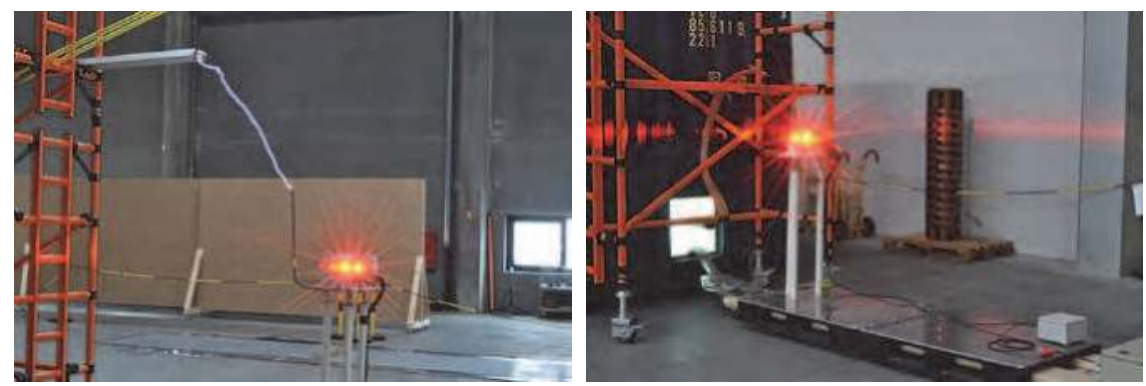

Fig. 5. A test of aircraft warning light, conducted using both impulse voltages and impulse currents, BTI Light systems A/S and Testinglab Denmark ApS.

\section{Numerical modelling}

Numerical modelling covers a wide range of mathematical tools to describe the physics of a certain structure or phenomenon. Concerning verification of wind turbine designs, the two main issues of lightning protection, attachment process and current conduction are simulated individually.

\subsection{Modelling of lightning attachment points}

Traditionally, the lightning attachment points on wind turbines have been defined by the Electro Geometrical Methods (Rolling Sphere, Protective Angle and Protective Mesh). Considering the blades, it implies that air terminations (receptors) are typically distributed along the length from radius $20 \mathrm{~m}$ and outwards, although service experience shows that inboard receptors are only struck occasionally. Data supporting the fact that mainly the blade tips are struck was presented initially in 2006 (Madsen et al. 2006; Madsen et al. 2010). Based on the requirements in the IEC 61400-24 of mandatory verification, numerical tools capable of evaluating and verifying wind turbine blade protection designs have been invented.

\subsubsection{Lightning research}

In the quest of defining an appropriate model for determining the risk of lightning attachment points on wind turbines, it is valuable to investigate the tendencies in the lightning research community. Several research teams have worked with analytical and numerical methods to describe the attachment process. Results have been presented in scientific journals and lightning conferences.

The leader progression model developed by Dr. Marley Becerra and Professor Vernon Cooray considers all the physical relations and criteria governing the inception and stable 
propagation of the upward or connecting leader (Becerra, M. 2008). Their research is based on work by several other researchers during the past decades, and by comparing and combining these diverse theories, they have developed a unique model that considers the potential distribution surrounding grounded objects and the criteria for the inception of a stable positive upward leader.

Two cases apply for the positive upward leader. The first part considers the inception of a stable upward leader in the case of a static background field. Such a situation precedes the formation of an upward initiated lightning strike of negative polarity. In the second case, the electric field around the grounded structure is affected by a descending negative stepped leader, which means that the inception processes involve some dynamics.

The static version of the leader progression model has been verified using rocket triggered and altitude triggered lightning, and now it is used to evaluate the different characteristics of positive upward leaders. Only cloud-to-ground lightning flashes of negative polarity are treated by the model, corresponding to $90 \%$ of all naturally occurring lightning flashes. The remaining $10 \%$ are not covered by the present algorithms.

The engineering application intend to apply the highly scientific theories onto a physical structure like a wind turbine, and thereby develop an engineering tool that can be used to verify future wind turbine designs according to the IEC 61400-24.

\subsubsection{Physical model}

The recently used model to determine the attachment point distribution refers to the set of equations and algorithms presented in 2005 (Becerra, et al. 2005), and implemented in 2007, 2008 and 2009 (Bertelsen et al. 2007; Madsen et al. 2008, Madsen et al. 2009). Compared to the initial algorithms, the present set of equations now considers a static model where a downward leader is incorporated covering both upward and downward initiated lightning of negative polarity. The main physical parameters and conditions for incepting the positive leader from the grounded structure are the same for the early and the present models. The only difference is how the algorithm defines the striking inception distance and the associated attachment distribution.

\subsubsection{Physics}

Before a negative lightning strike occurs to a specific point on a structure, a leader is incepted from the point and propagates towards the charged region in the cloud (upward lightning) or the tip of the approaching stepped leader (downward lightning). It is generally believed that the point, which incepts the self-propagating leader, initially is also the point that will intercept the lightning strike (Golde, R.H. 1977). This leads in the direction that the point with the lowest stabilisation field (the least electric field sufficient for the inception of a stable and successful upward leader) will also incept an upward leader first and hence be the point struck by lightning.

However, since this is not the case that one single point receives all lightning attachments, the research team at Uppsala recommends that 'static leader inception zones' for each point in concern must be evaluated, and that the lateral coverage of these zones can be related to the probability of each point being struck.

Static leader inception is said to occur when the conditions for incepting a stable upward leader for a certain point is fulfilled, by the presence of a downward leader when the electric fields are calculated without considering the dynamics of the downward leader. Although 
introduction of a downward leader contradicts the definition of an upward initiated strike, the static leader inception zones are still used for evaluating both upward and downward initiated lightning (Becerra, M. 2008).

The static leader inception zone of a single point for a specific prospective peak current is defined as the horizontal area within which the tip of the downward leader at a certain but not constant height will incept a self-propagating upward leader. The principle is illustrated in Fig. 6: If a downward negative leader intrudes the horizontal area defined as the static leader inception zone, the corner of the building (green point) will incept a stable upward leader. If the vertical downward leader approaches outside this area, the conditions for incepting a stable upward leader at the green point is not met, and the lightning will strike elsewhere. Since the downward leader approaches at different lateral distances from the structure, the upward leader inception will occur when the downward leader tip is at different heights. Especially when the downward leader approaches outside of the structure, the leader will get closer to ground before inception of the upward leader from the point on the structure.

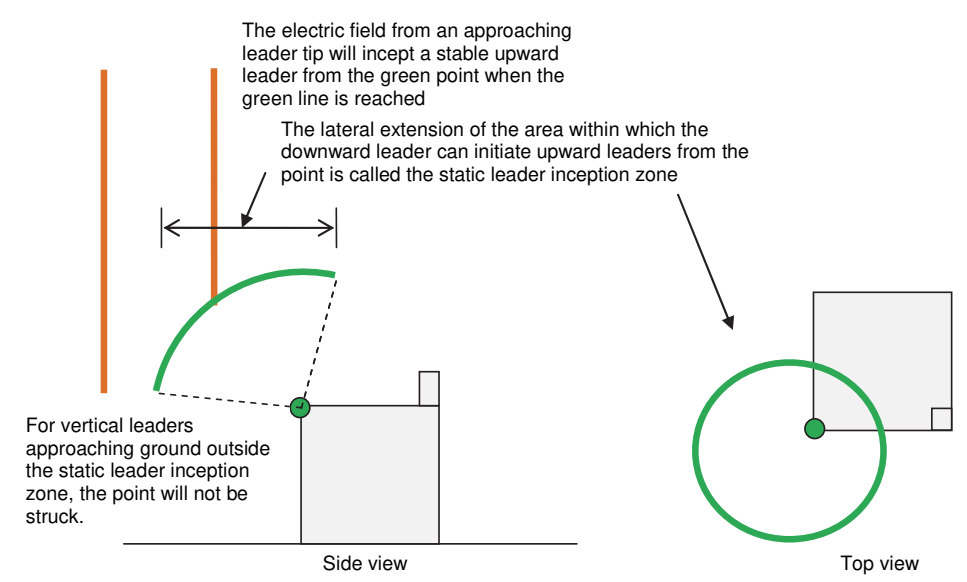

Fig. 6. The static leader inception zone used to evaluate the probability of each point incepting an upward leader.

If more than one point on a structure is considered, by independant treatment the static leader inception zones might coincide, so that the conditions for incepting an upward leader will be met at several points, if the downward leader approaches along the same vertical line. However, when this occurs it is unlikely that the different points will incept upward leaders for the same height of the downward leader, meaning that one of the points will incept the upward leader before the others, i.e. at a larger height of the downward leader.

On Fig. 7, a second point (blue) is considered exhibiting a larger inception zone at higher altitudes relative to the green point. Because the blue point will incept upward leaders at higher altitudes of the downward leader tip, when the downward leader approaches as shown, the blue inception zone covers the green inception zone. When correlating the inception zones with the probabilities, the blue area will attract more lightning strikes than the green area, meaning that the blue point is more exposed. 
Consequences of following these principles: For each coordinate in the horizontal X-Y plane there exists a height of a vertical downward leader which corresponds to the inception of an upward leader from one single point on the structure considered. This single point on the structure will be the one struck by lightning if a vertical leader approaches along the specific $\mathrm{X}-\mathrm{Y}$ coordinate.

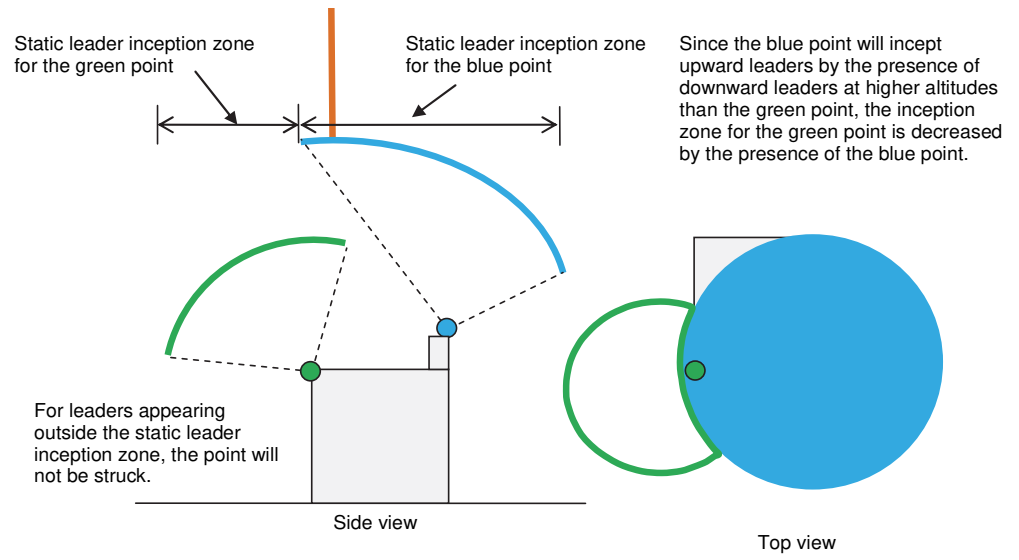

Fig. 7. If static leader inception zones coincide, the "area" will be given to the point that incepts the upward leader first.

The analysis must be conducted for several prospective peak currents, since the prospective peak current defines the charge distribution along the downward leader and hence the electric field surrounding each point on the structure. In the following section an algorithm is described which incorporates the principle of finding the single point on the structure that fulfils the upward leader inception criteria first, and thereby a method of assigning the static leader inception zones uniquely.

\subsubsection{Algorithm}

Two corners of a building are shown in a 2D plot on Fig. 8. The green and blue circle segments show the distances from the two corners (green and blue), at which a tip of a downward leader with a prospective peak return stroke current as indicated will initiate the inception of a stable upward leader from the corner considered. A larger prospective peak current implies that the inception of upward leaders will occur at larger distances, whereas smaller peak currents mean that the tip of the downward leader has to get closer to the point in concern to incept upward leaders.

A vertical downward leader is introduced along a fixed number of $X-Y$ coordinates (only $X$ coordinates on the drawing of Fig. 8) and extended to different heights or $Z$ coordinates. For each location of the downward leader tip $(x, y, z)$ and each of several different prospective peak currents, the electric field, and hence the conditions for incepting upward leaders from each point on the structure, is evaluated. Once the conditions are fulfilled for one point, the specific values of leader tip coordinates $(\mathrm{x}, \mathrm{y}, \mathrm{z})$, the point for which the conditions are fulfilled $\left(\mathrm{P}_{\mathrm{i}}\right)$ and the prospective peak current $\left(\mathrm{I}_{\mathrm{p}}\right)$ are noted. Such a data set is seen on Fig. 8 concerning a vertical downward leader approaching the structure along $\left(\mathrm{x}_{\mathrm{dl}}, \mathrm{y}_{\mathrm{dl}}\right)$, defined by a prospective return stroke current of $20 \mathrm{kA}$, and extended to a height $\left(\mathrm{z}_{\mathrm{dl}}\right)$ intersecting the $20 \mathrm{kA}$ striking inception distance for the green point. 


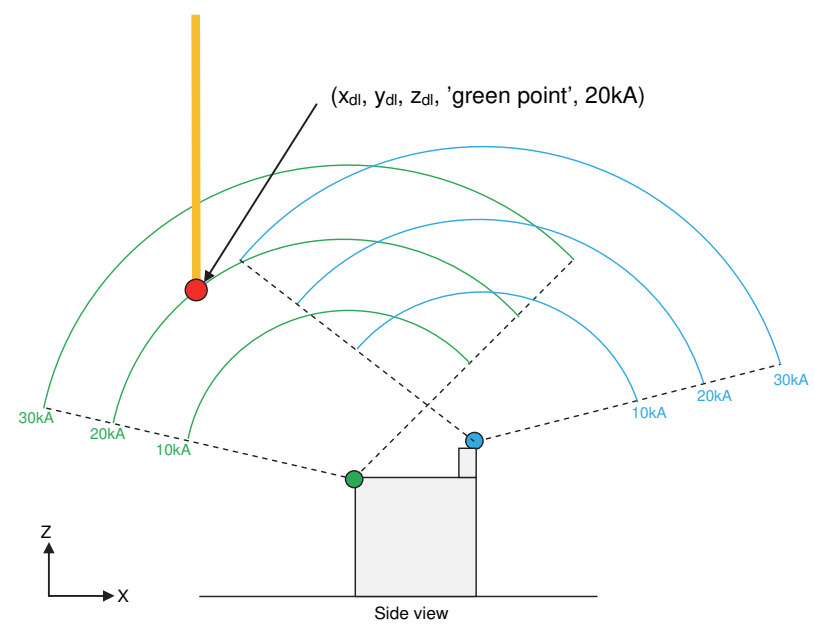

Fig. 8. Illustration of the algorithm for calculating static leader inception zones.

When a fine grid of coordinates for the downward leader tip are considered and the inception conditions for different prospective peak currents are evaluated in each coordinate, the acquired data sets will describe the coloured segments shown on Fig. 9. Here the area described by the lateral extension of each segment is defined as the stable leader inception zone for the corresponding peak return stroke current.

As mentioned, the evaluation of probabilities is done by considering the individual areas of the stable leader inception zones and relating them to the total stable leader inception zone of the structure.

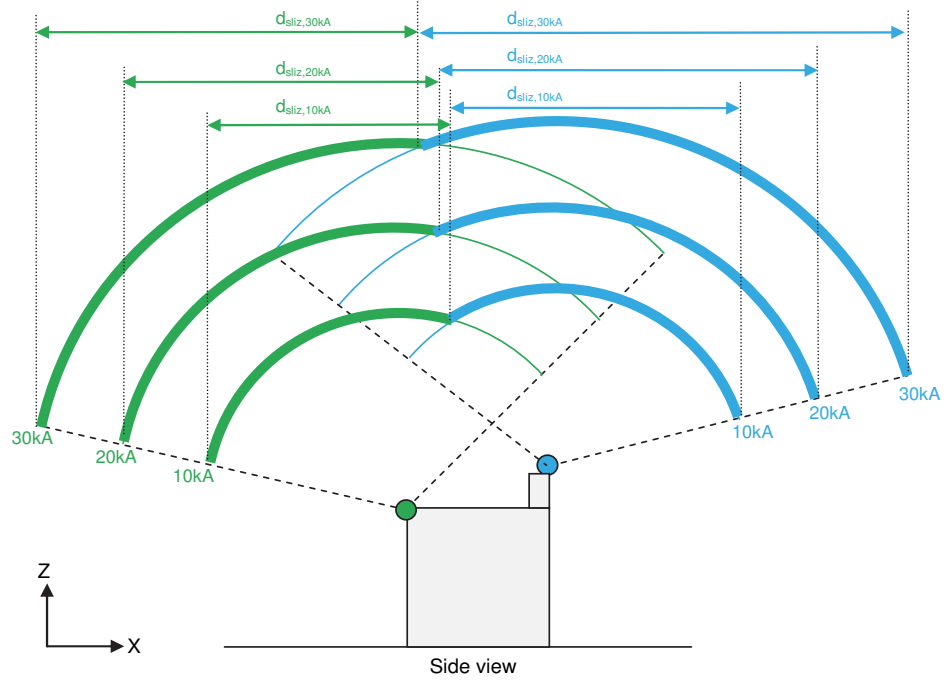

Fig. 9. The lateral extensions of the coloured segments for each peak current are the static leader inception zones. 
On Fig. 10, a top view of the two points on the building considered previously is shown. The red dots correspond to each X-Y coordinate in which the vertical leader has approached the structure and the green and blue areas show the lateral extension of the stable leader inception zones considering a fixed prospective peak current.

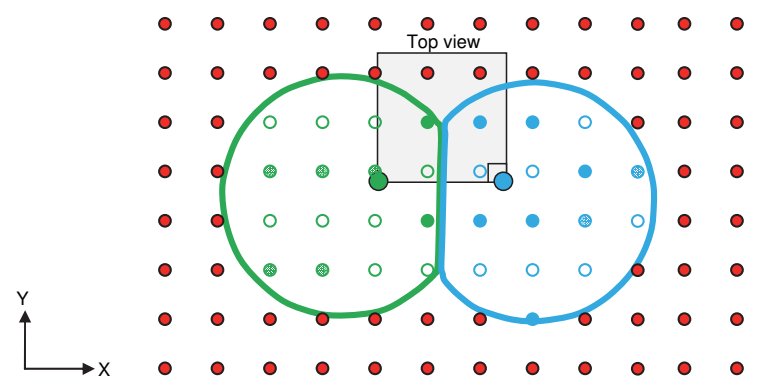

Fig. 10. The probabilities are evaluated based on the individual stable leader inception zones, for different fixed prospective peak currents.

The individual stable leader inception zones are found by determining which of the points, will incept a stable leader (in this case two points). The number of downward leader locations within the areas is proportional to the areas. Fig. 10. represents an example: The number of green points relative to the sum of green and blue points approximates the green area relative to the sum of the green and the blue area and hence the probability that the green point will be struck.

\subsubsection{Case study}

To verify the applicability of the simulation tool, a case study with a modern wind turbine is conducted. Several points along the blades and on the nacelle are considered. The final outcome is the probability of each point being struck. The calculations are performed with prospective peak currents of $60 \mathrm{kA}, 40 \mathrm{kA}, 20 \mathrm{kA}$ and $10 \mathrm{kA}$. For higher or lower peak currents, the consequences are to be extrapolated based on these values.

Initially a 3D model of the wind turbine is defined within a box shaped analysis volume in a Finite Element Model (FEM) environment, Fig. 11. The size of the analysis volume is selected several times larger than the largest dimension of the turbine. Before assigning boundary conditions, the turbine model is subtracted from the analysis volume leaving only a single domain (between the turbine exterior and the boundaries of the analysis volume) for the analysis. The entire surface of the wind turbine as well as the ground at which it is standing is defined by a $0 \mathrm{~V}$ boundary condition. The vertical boundaries of the analysis volume are assigned a boundary condition stating that the normal component of the electric displacement is zero (the potential is symmetric with respect to the boundary) and the upper horizontal boundary of the analysis volume is assigned a certain potential.

Poisson's equation is solved for the domain, and the vertical potential distribution above each point in concern is used as input to the following algorithms. The algorithms describe how this potential distribution is coupled with theoretical discharge physics, finally resulting in a quantity for each point known as the electric stabilisation field (Becerra, M. 2008). The electric field is calculated as the potential on the upper boundary necessary for 

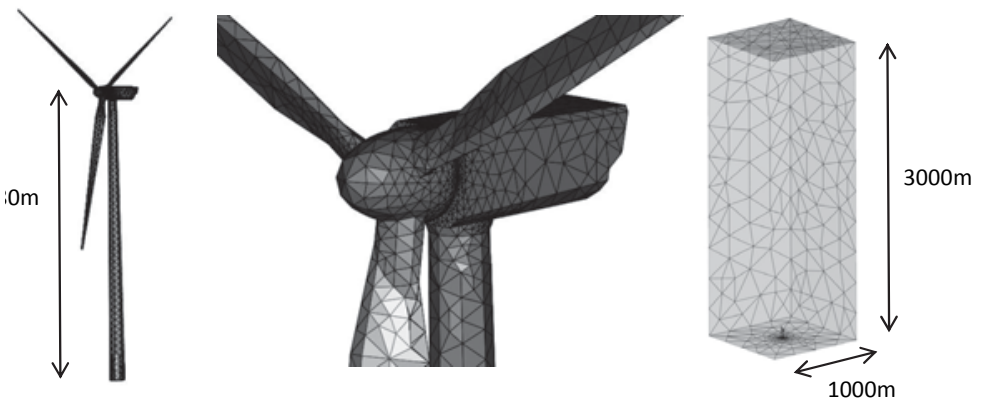

Fig. 11. A typical model of a turbine used in the research. The size of the analysis volume is considerably larger than the turbine, in this case $1 \mathrm{~km} \times 1 \mathrm{~km} \times 3 \mathrm{~km}$.

fulfilling the inception conditions divided by the height of the analysis volume, whereas the term successful upward leader refers to a leader that will propagate upwards self consistently.

Having the stabilisation field defined for each point on the structure, the second part of the process is to follow the procedure for assigning static leader inception zones, finally resulting in individual probabilities as seen above. To understand the basis of the discrete probabilities, 3D scatter plots of the successful leader inception points for the orientation $30^{\circ}$ to horizontal level are shown in Fig. 12. Here it is clear how the upward leader inceptions occur with a larger distance to the downward leader tip for higher prospective peak currents (Left), whereas lower prospective peak currents allow the downward leader to approach closer to the turbine before upward leader inception (Right).

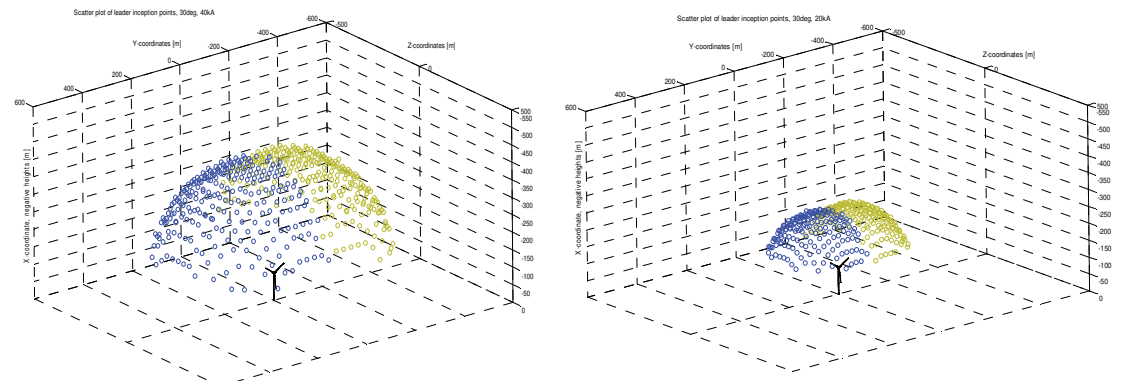

Fig. 12. Scatter plots showing origins of the downward leaders, leading to successful upward leader inception. Each colour corresponds to different attachment points. Left: 40kA, Right 20kA.

By evaluating the results presented graphically on Fig. 12 for three different rotor orientations and the four different peak current levels, an indication of the attachment point distribution for all possible situations is derived. In practice, it is done by counting the number of points with each individual colour and relating them to the total number of points (corresponding to the static leader inception zone defined previously). On Fig. 13, examples of the results considering two different rotor orientations and the 18 different points incepting lightning strikes are shown. 


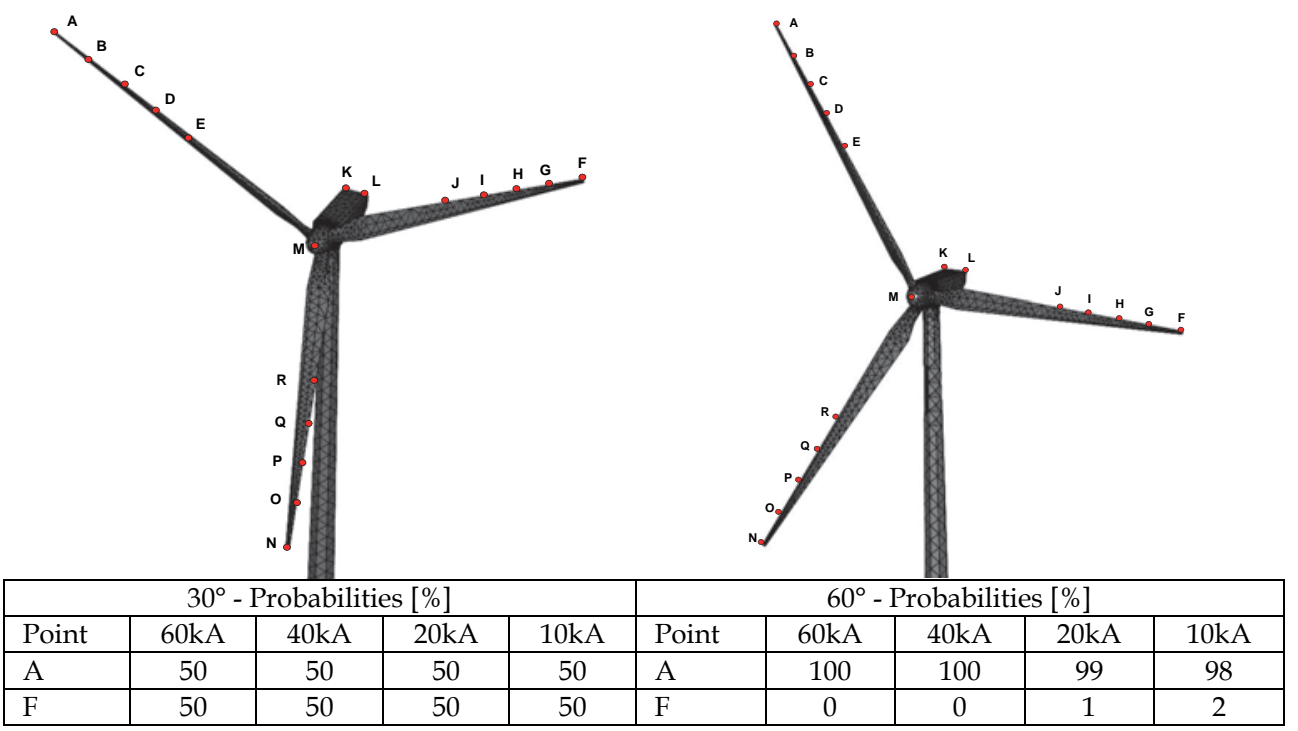

Fig. 13. Attachment point distribution along five points for each blade, two points on the rear of the nacelle and the tip of the spinner.

In Fig 13. it is seen how the blade tips are the only exposed structures to peak currents down to $10 \mathrm{kA}$ and that the attachment distribution dictates equal probability for each of the upward pointing blades in the $30^{\circ}$ orientation. For the second orientation $\left(60^{\circ}\right.$ with horizontal), the probability of striking the upward pointing blade is by far larger than the probability of striking other parts of the turbine. However, as indicated in Fig. 13, the probability of striking the blade tip on the horizontal blade (point F) increases as the peak current is lowered.

Intuitively, the general conclusion based on the probabilities found above seems too simple. However, they depend strictly on the geometry and the algorithms derived. By investigating the situation having the rotor in the $30^{\circ}$ orientation, the differences at the different peak return stroke currents are clarified. Fig. 14 shows three views of the turbine along with the points representing the leader tip positions at the successful inception of the upward leader. The blue points correspond to the situation where point A incepts upward leaders, whereas the green points represent the situations where point $F$ receives the lightning strike.
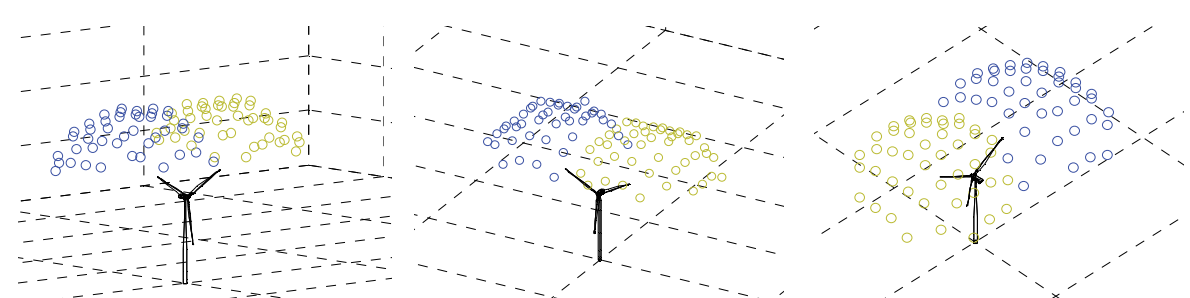

Fig. 14. Scatter plots visualising the $30^{\circ}$ orientation considering $10 \mathrm{kA}$ prospective peak currents. 
On Fig. 15 two plots of the same data are shown with a view parallel to the rotor axis and from directly above the turbine. In each case it is seen how the sphere caps drawn by the coloured points tend to wrap the turbine more smoothly at such low peak currents, so that the turbine geometry becomes more apparent to the leader tip. At high peak currents only the turbine extremities are exposed, whereas for low peak currents suddenly the less exposed structures on the turbine might incept lightning strikes.
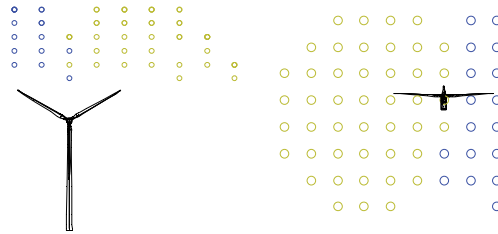

Fig. 15. Scatter plots shown parallel to the rotor axis (left) and from directly above the turbine (right), 10kA prospective peak current.

If full simulations were to be conducted at even smaller peak currents, the tendency would be that suddenly inboard receptors or the rear of the nacelle would be exposed enough to incept direct lightning strikes. However, at such low peak currents the associated damages are easier to control by suitable protection measures.

To prove this tendency, a simple situation is simulated manually by a vertical leader approaching directly above the turbine. Fig. 16 shows the leader tip height at connecting leader inception as well as the points from which the inception occurs for different peak currents. When lowering the current, the height of inception is lowered as well, meaning that the leader tip gets closer to the turbine before anything happens. Down to $8.5 \mathrm{kA}$, the blade tip still incepts the connecting leaders first (A and F). At $8.25 \mathrm{kA}$ and $8 \mathrm{kA}$, the fifth receptor pair (E and $\mathrm{J}$ ) tends to incept leaders initially. The blade tips are not struck in this case. Lowering the current even further down to $7 \mathrm{kA}$ results in the exposure of the rear of the nacelle, since points $\mathrm{K}$ and $\mathrm{L}$ now incepts the initial leaders.

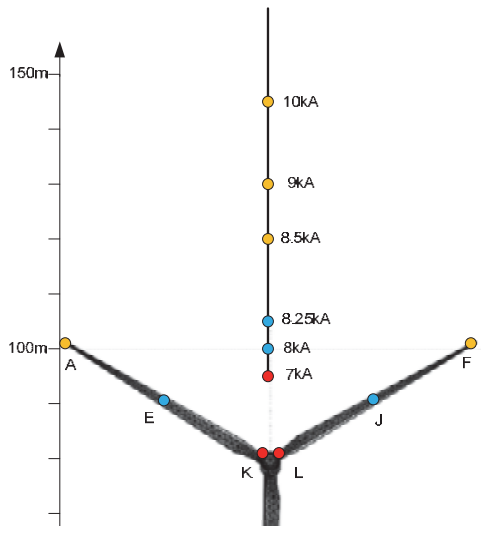

Fig. 16. By lowering the prospective peak return stroke current, attachment points elsewhere than the blade tips becomes possible. 
Considering higher peak currents than the 60kA used in these simulations, the attachment distribution would be similar, as shown in the $60 \mathrm{kA}$ simulations, since the sphere caps will move further away from the turbine. The findings using vertical leaders therefore shows that inboard parts of the structure are only exposed to small amplitude lightning strikes, and that lightning strikes having peak amplitudes in excess of 10kA will attach to the blade tips.

\subsubsection{Application of attachment point modelling}

Modelling of the lightning attachment points on wind turbines is used to foresee where and with which amplitudes the lightning discharge will affect the structure. This enables the lightning protection engineer to place adequate protection measures at the right locations without over-engineering the solutions. To get the turbine designs certified by DNV, GL or similar, it requires that the protection principles applied are verified according to IEC 6140024. Here either testing or modelling becomes necessary.

In the larger perspective, numerical modelling has also been used to address the issues of subdividing the wind turbine blades into lightning protection zones. The principle is known from the avionics industry, were the areas of an aircraft fuselage or a wing is divided into zones struck directly, experiencing a swept stroke, hang on zones and similar (SAE ARP 5414). The reason for considering zoning as an important part of the lightning protection design is that damages and attachment points inboard the blade tips - foreseen by the general EGM methods - are not experienced. Data from recent field surveys on modern wind turbines indicate that mainly attachments at the blade tips occur (Madsen et al. 2010).
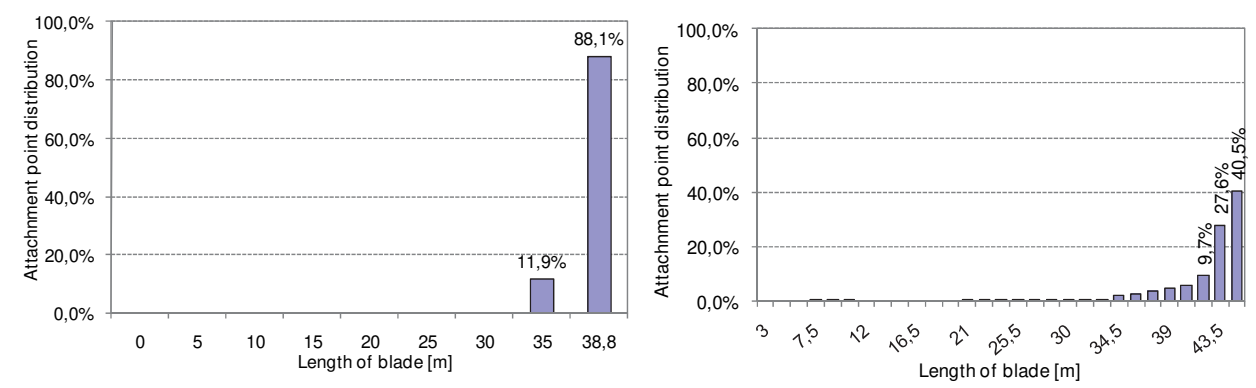

Fig. 17. Left: Attachment point distribution on 236 blades (39m) after two years of lightning exposure at the 'Horns Rev' wind farm, Right: Attachment point distribution of 2818 identified lightning attachment points on $45 \mathrm{~m}$ blades.

From both graphs on Fig. 17 it is obvious how the blade tips are most favoured when it comes to lightning attachment. The main conclusion from the recent site inspection program is that the tip of the blades (within $1.5 \mathrm{~m}$ ) receives $70 \%$ of the lightning strikes, that $90 \%$ of the lightning strikes attaches within the outermost $6 \mathrm{~m}$ of the blade, and that the remaining $10 \%$ attaches further inboard (6m from the tip). No correlations have been done so far considering the size of the erosion on receptors, and hence the current peak amplitude / specific energy / charge levels, but these are topics that will be addressed by the research team in future publications.

Based on the field surveys, and heavily supported by the numerical computations, it was therefore decided to define a zoning concept of wind turbine blades according to Fig. 18. 


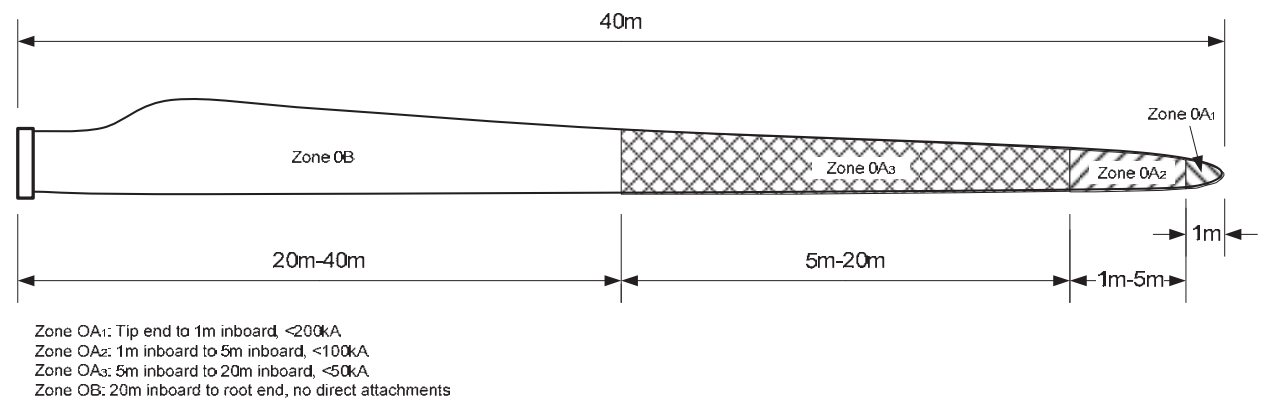

Fig. 18. New zoning concept based on the expected peak current amplitudes. (Madsen et al. 2010)

The zoning concept is regarded a possible upgrade for the test requirements in the next revision of the IEC 61400-24.

\subsection{Modelling of magnetic fields}

When a DC current is injected through a complex structure with several different paths, the current will be distributed according to the resistances of the different paths. There are no mutual couplings of neither inductive nor capacitive nature, since the currents or voltages are not time dependant. The solution of the current distribution is then straightforward, and can be performed using simple linear algebra.

If $\mathrm{AC}$ currents or transient currents are injected, the $\mathrm{dI} / \mathrm{dt}$ of the $\mathrm{AC}$ current or the $\mathrm{dU} / \mathrm{dt}$ of the AC voltage will introduce mutual couplings, which means that the current flowing in one conductor might induce a voltage on another conductor, or vice versa. In this case, the mutual couplings must be identified. It can be done analytically on very simple structures (two parallel wires, two wires of infinite length crossing at a fixed angle, etc.), but when it comes to real physical structures, numerical methods are required.

The numerical codes typically used are based on the FDTD (Finite Difference Time Domain) or the FEM (Finite Element Method). In both cases, the structure geometry is subdivided into a finite number of elements, and Maxwell Equations are then solved for each element respecting the mutual boundary conditions.

\subsubsection{Current components}

To model voltage drops during the interception of a lightning strike, the different components of the lightning strike must be considered individually. In the international standards for lightning protection, three characteristic current components for a Level 1 stroke are derived:

- The first return stroke, a 200kA current pulse with a rise time of $10 \mu$ s and a decay time of $350 \mu \mathrm{s}$. In the frequency domain, this waveform is simulated by an oscillating waveform exhibiting a frequency of $25 \mathrm{kHz}$.

- The subsequent return stroke, a 50kA current pulse with a rise time of $0.25 \mu$ s and a decay time of $100 \mu \mathrm{s}$. In the frequency domain, this waveform is simulated by an oscillating waveform exhibiting a peak frequency of $1 \mathrm{MHz}$.

- The continuing current, a DC current pulse of amplitude 200-800A and duration of up to a second. 
In natural lightning, all possible combinations occur, but for verification of lightning protection systems (simulation and testing) these three individual components apply. In the case of determining the maximum magnetic fields within the nacelle, the first and the subsequent return stroke are of most concern.

Due to the frequencies of the lightning current and the permeability of the involved conductor materials for the nacelle structure, the skin effect becomes very important. Considering Iron with a relative permeability of 200 and conductivity in the range of $10^{7}$ $\mathrm{S} / \mathrm{m}$, the skin depth for a $10 \mathrm{kHz}$ current component will be only $0.11 \mathrm{~mm}$, decreasing with increasing frequency. Therefore, the high frequency model $(>10 \mathrm{kHz})$ treats the solid structure of the nacelle as thin boundaries, since it can be assumed that all current flows at the structure extremity.

\subsubsection{Modelling output}

The simulations consider several different attachment points for the lightning strike, by injecting the lightning current into different places at the nacelle. A typical model of a wind turbine considering magnetic fields and current distribution when a blade is struck is seen on Fig. 19.
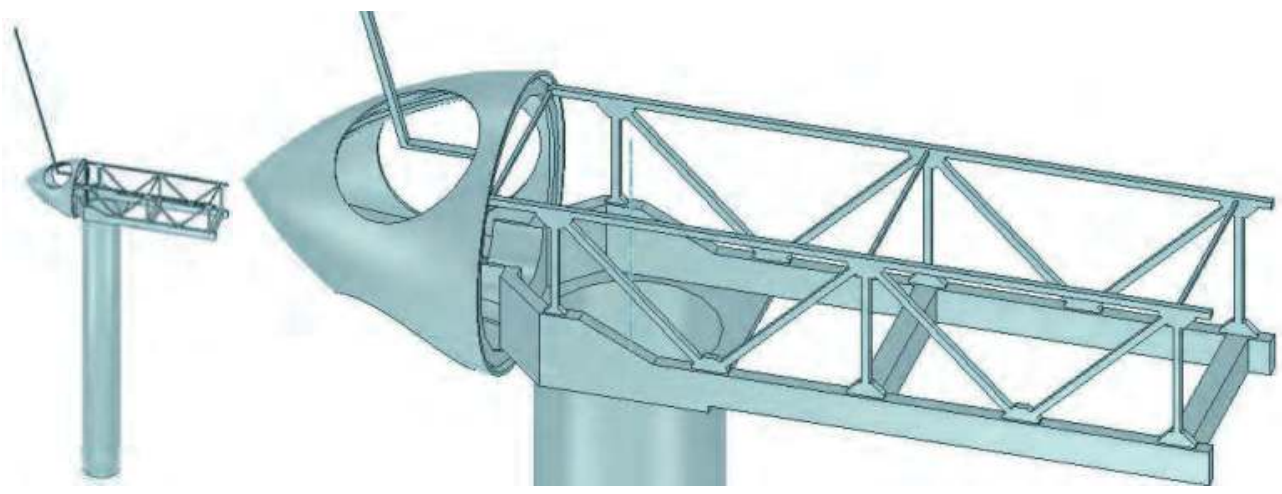

Fig. 19. The configuration where the turbine is struck on a blade pointing to the left with an angle of $45^{\circ}$ with horizontal. The line extending from the HUB is simulating the blade down conductor.

In the case of a lightning strike to a blade located on the left side of the nacelle, the magnitude of the magnetic field during the first return stroke $(200 \mathrm{kA} @ 25 \mathrm{kHz})$ is illustrated on Fig. 20.

The magnetic field is visualized by drawing surfaces of equal magnitude. The red surface represents an area where the magnetic field attains a value of $30 \mathrm{kA} / \mathrm{m}$, the green surface represents a value of $20 \mathrm{kA} / \mathrm{m}$, the light blue surface represents a value of $10 \mathrm{kA} / \mathrm{m}$ and the dark blue a value of $5 \mathrm{kA} / \mathrm{m}$.

The magnitude and distribution of the magnetic field around the geometry depends on the current path and current density on the surface of the structure. By evaluating the field distribution on Fig. 20, it is seen that the highest field strengths are obtained close to the main current paths where these are of limited size (the down conductor, lightning channel, etc.). At the rear of the nacelle and around the structural bars some metres away from the 
HUB, the field is much lower. The current flowing in the nacelle construction works as the current in a faraday cage; hence the magnetic field in the centre of the nacelle is cancelled out to some degree.
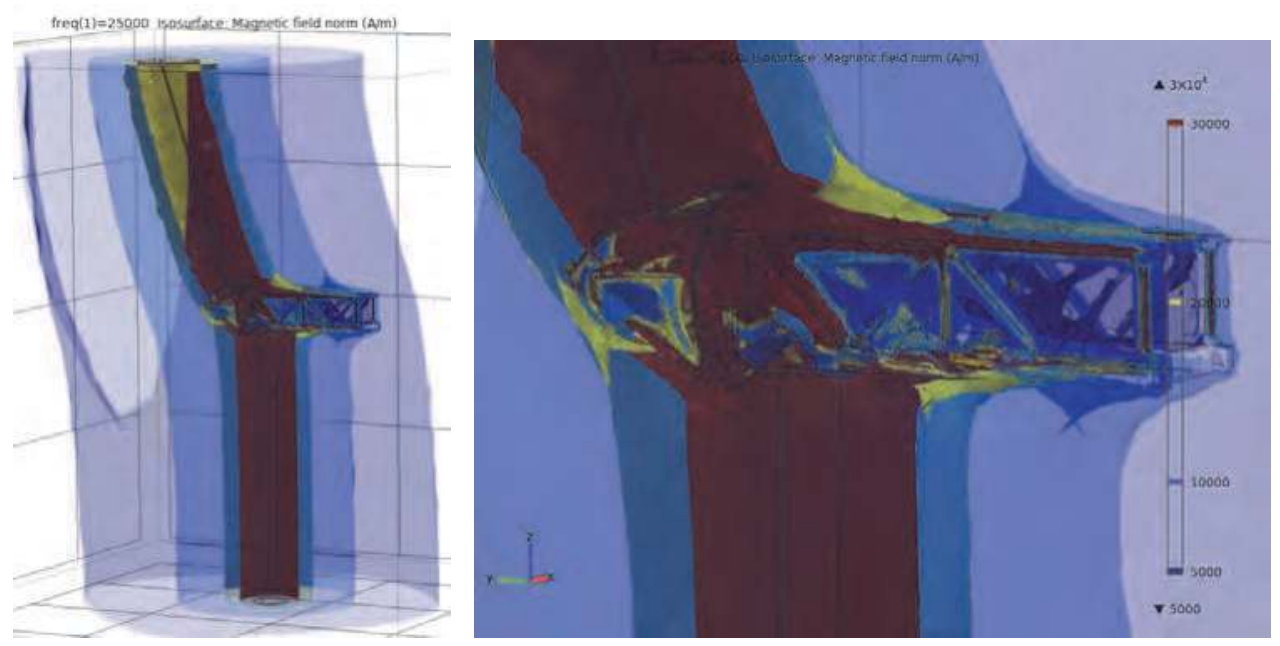

Fig. 20. Illustration of the magnetic field magnitude during a first return stroke represented by $200 \mathrm{kA}$ at $25 \mathrm{kHz}$. The magnetic field is visualized by an iso-surface plot in which red represents a magnetic field strength of $30 \mathrm{kA} / \mathrm{m}$, green represents $20 \mathrm{kA} / \mathrm{m}$, light blue represents $10 \mathrm{kA} / \mathrm{m}$ and dark blue represents a field strength of $5 \mathrm{kA} / \mathrm{m}$. Magnetic fields strength above $30 \mathrm{kA} / \mathrm{m}$ and below $5 \mathrm{kA} / \mathrm{m}$ has been omitted to simplify the illustration.

The current distribution within the different structural components also tends to minimize the magnetic field in the centre of the nacelle. This is seen more clearly at the following 2D slice plot, where the magnitude of the magnetic field is plotted for two different slice plots.


Fig. 21. 2D slice plot of the magnetic field when $200 \mathrm{kA}$ at $25 \mathrm{kHz}$ is conducted from one of the blades towards the tower base. The range for the plot is $5 \mathrm{kA} / \mathrm{m}$ (blue) to $30 \mathrm{kA} / \mathrm{m}$ (red). 
The magnetic field is forced to the outside of the nacelle structure, due to the mutual coupling between the current flowing in the different structural components. The consequence is that the structural bars act as a Faraday cage for the interior of the nacelle, which is to be considered when placing panels and cables within the nacelle.

\subsubsection{Application of results}

Once the magnetic fields within the structure are known, panels and shielded cables can be selected to ensure certain compatibility between the control and sensor systems within the nacelle and the environment in terms of magnetic fields. Based on the current distribution also obtained by the numerical simulations, expressions can be derived, which couple lightning currents in the main structure with induced currents in cable shields.

Having the currents flowing on shielded cable or EMC enclosures with well-known transfer impedance, finally enables the designer to calculate the expected potential rise on conductors and hence select appropriate surge protection.

Along with testing, it is believed that future verification will benefit considerably by numerical modelling of lightning protection systems.

\section{Conclusion}

The present chapter presents general aspects of lightning protection to be considered when designing lightning protection systems for wind turbines. Since the release of the new standard IEC 61400-24, for lightning protection of wind turbines, verification of the protection measures has become mandatory. The verification can be done by either high voltage or high current testing, or by means of numerical modelling that has previously been verified against experimental findings or field surveys.

The test programme begins with an Initial Leader Attachment Test, defining where the turbine or in most cases the blade will most likely be struck. Hopefully, the blade will only be struck at places designed to handle the lightning current (lightning receptors) otherwise the design must be improved before passing the blade on to the high current test.

After defining these possible attachment points, the blade is tested in a high current laboratory to be subjected to the threat of the lightning current. The various lightning current waveforms are injected into the locations determined by the high voltage test, and the damage or wearing associated with these tests might require further design optimisation.

At an early stage of a design phase or in situations where testing is not an option, numerical modelling can be used as mean of verification. Basically the same two phenomena are modelled, the attachment process and the current conduction.

Attachment point modelling aims at identifying possible lightning attachment points on the wind turbine and defines the probabilities that certain areas will receive strikes of certain amplitudes. The methodology is used to foresee the most optimum placement of air termination systems on the nacelle and the blades, which is no longer applicable to the EGM methods according to IEC 61400-24.

Simulation of current distribution and magnetic fields in especially the nacelle structure is vital for design engineers to require a sufficient degree of shielding for their equipment. The magnetic environment within or adjacent to the nacelle structure during a lightning strike, is considerably higher than what the general EMC standards describe. 


\section{Acknowledgement}

The research within lightning protection of wind turbines is carried out in a major community worldwide including representatives from the wind turbine manufacturers, wind turbine operators, test facilities, universities, public and private research institutes, etc. The knowledge accumulated within this group of researchers, and published at international conferences, in scientific journals and at commercial expos would not be possible without the involvement and professionalism of all participants.

A special acknowledgement is dedicated to friends and colleagues that have helped me and the wind turbine industry to gain a higher level of engineering expertise within lightning protection of wind turbines.

\section{References}

Madsen, S.F. (2006). Interaction between electrical discharges and materials for wind turbine blades particularly related to lightning protection, Ørsted-DTU, The Technical University of Denmark, Ph.D. Thesis, ISBN: 87-91184-60-6

Larsen, F.M \& Sorensen, T. (2003). New lightning qualification test procedure for large wind turbine blades, Proceedings of International Conference on Lightning and Static Electricity, Blackpool, UK.

Madsen, S.F., Holboll, J., Henriksen, M., Bertelsen, K. \& Erichsen, H.V. (2006) New test method for evaluating the lightning protection system on wind turbine blades. Proceedings of the 28th International Conference on Lightning Protection, Kanazawa, Japan.

Holboll, J., Madsen, S.F., Henriksen, M., Bertelsen, K. \& Erichsen, H.V. (2006) Lightning discharge phenomena in the tip area of wind turbine blades and their dependency on material and environmental parameters. Proceedings of the 28th International Conference on Lightning Protection, Kanazawa, Japan.

Bertelsen, K., Erichsen, H.V. \& Madsen, S.F. (2007) New high current test principle for wind turbine blades simulating the life time impact from lightning discharges. Proceedings of the 30th International Conference on Lightning and Static Electricity, Paris, France.

IEC 61400-24 Ed. 1.0. Wind turbines - Part 24: Lightning Protection, 2010.

IEC TR 61400-24. Wind turbine generator systems - Part 24: Lightning protection, 2002.

SAE ARP 5416. Aircraft Lightning Test Methods, Section 5: Direct Effects Test Methods, 2004.

IEC 62305-1 Ed. 1.0. Protection against lightning - Part 1: General principles, January 2006.

EN 50164-1 Lightning Protection Components (LPC) - Part 1: Requirements for connection components, September 1999.

Heater, J. and Ruei, R. (2003). A Comparison of Electrode Configurations for Simulation of Damage Caused by a Lightning Strike, Proceedings of International Conference on Lightning and Static Electricity, Blackpool, UK.

IEC 62305-2 Ed. 1.0, Protection against lightning - Part 2: Risk management, January 2006.

IEC 61000-4-5 Ed. 2.0, Electromagnetic compatibility (EMC) - Part 4-5: Testing and measurement techniques - Surge immunity test, November 2005.

Madsen, S.F., Bertelsen, K., Krogh, T.H., Erichsen, H.V., Hansen, A.N., Lønbæk, K.B. (2010) Proposal of new zoning concept considering lightning protection of wind turbine 
blades. Proceedings of the 30th International Conference on Lightning Protection, Calgari, Italy.

Becerra, M. (2008) On the Attachment of Lightning Flashes to Grounded Structures, Doctoral thesis, Uppsala University, ISBN :XXXX.

Becerra, M. and Cooray, V. (2005) A simplified model to represent the inception of upward leaders from grounded structures under the influence of lightning stepped leaders, Procedings of the 29th International Conference on Lightning and Static Electricity, Seattle Washington, USA.

Becerra, M., Cooray V. \& Abidin H.Z. (2005) Location of the vulnerable points to be struck by lightning in complex structures, Procedings of the 29th International Conference on Lightning and Static Electricity, Seattle Washington, USA.

Bertelsen, K., Erichsen, H.V., Skov Jensen M.V.R. \& Madsen, S.F. (2007) Application of numerical models to determine lightning attachment points on wind turbines, Proceedings of the 30th International Conference on Lightning and Static Electricity, Paris, France.

Madsen, S.F. \& Erichsen, H.V. (2008) Improvements of numerical models to determine lightning attachment points on wind turbines, Procedings of the 29th International Conference on Lightning Protection, Uppsala, Sweden.

Cooray, V., Rakov, V. \& Theethayi, N. (2004) The relationship between the leader charge and the return stroke current - Berger's data revisited, Procedings of the 27th International Conference on Lightning Protection, Avignon, France.

Madsen, S.F. \& Erichsen, H.V. (2009) Numerical model to determine lightning attachment point distributions on wind turbines according to the revised IEC 61400-24, Proceedings of the 31st International Conference on Lightning and Static Electricity, Pittsfield, Massachussetts, USA.

Golde, R.H. (1977) Lightning Conductor, Chapter 17 in Golde, R.H. (Ed.), Lightning, vol. 2, Academic Press: London, UK.

SAE ARP 5414. Aircraft Lightning Zoning, 1999. 


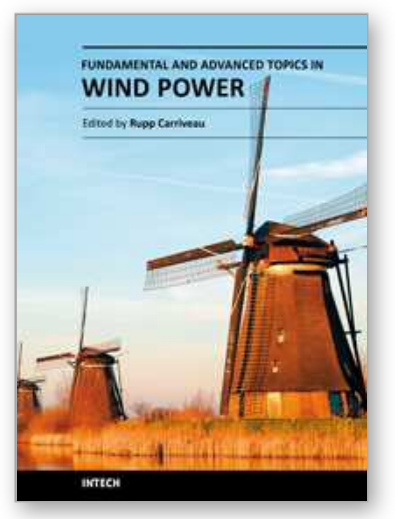

\author{
Fundamental and Advanced Topics in Wind Power \\ Edited by Dr. Rupp Carriveau
}

ISBN 978-953-307-508-2

Hard cover, 422 pages

Publisher InTech

Published online 20, June, 2011

Published in print edition June, 2011

As the fastest growing source of energy in the world, wind has a very important role to play in the global energy mix. This text covers a spectrum of leading edge topics critical to the rapidly evolving wind power industry. The reader is introduced to the fundamentals of wind energy aerodynamics; then essential structural, mechanical, and electrical subjects are discussed. The book is composed of three sections that include the Aerodynamics and Environmental Loading of Wind Turbines, Structural and Electromechanical Elements of Wind Power Conversion, and Wind Turbine Control and System Integration. In addition to the fundamental rudiments illustrated, the reader will be exposed to specialized applied and advanced topics including magnetic suspension bearing systems, structural health monitoring, and the optimized integration of wind power into micro and smart grids.

\title{
How to reference
}

In order to correctly reference this scholarly work, feel free to copy and paste the following:

Soren Find Madsen (2011). Verification of Lightning Protection Measures, Fundamental and Advanced Topics in Wind Power, Dr. Rupp Carriveau (Ed.), ISBN: 978-953-307-508-2, InTech, Available from: http://www.intechopen.com/books/fundamental-and-advanced-topics-in-wind-power/verification-of-lightningprotection-measures

\section{INTECH}

open science | open minds

\author{
InTech Europe \\ University Campus STeP Ri \\ Slavka Krautzeka 83/A \\ 51000 Rijeka, Croatia \\ Phone: +385 (51) 770447 \\ Fax: +385 (51) 686166 \\ www.intechopen.com
}

\author{
InTech China \\ Unit 405, Office Block, Hotel Equatorial Shanghai \\ No.65, Yan An Road (West), Shanghai, 200040, China \\ 中国上海市延安西路65号上海国际贵都大饭店办公楼 405 单元 \\ Phone: +86-21-62489820 \\ Fax: +86-21-62489821
}


(C) 2011 The Author(s). Licensee IntechOpen. This chapter is distributed under the terms of the Creative Commons Attribution-NonCommercialShareAlike-3.0 License, which permits use, distribution and reproduction for non-commercial purposes, provided the original is properly cited and derivative works building on this content are distributed under the same license. 